service 50 pence, and several of these are considerably cheaper than the capital outlay required for an insulin syringe pump.

We have estimated plasma glucose concentration two-hourly on seven patients. We found that the range of results obtained was less than that of Drs T E T West and C Lowy (14 May, p 1252) and that the plasma glucose concentration at delivery, $5 \cdot 6 \pm 0 \cdot 3$ $\mathrm{mmol} / \mathrm{l}(101 \pm 5.4 \mathrm{mg} / 100 \mathrm{ml})$, was lower than they reported. We also measured plasma potassium and found that this did not change. No patient became ketonuric.

This demonstrates that it is possible to attain good diabetic control during diabetic labour in any district hospital with a simple infusion method.

$$
\text { K G M M ALbERTI }
$$

Southampton General Hospital,

Southampton, Hants

D J B THOMAS

Basingstoke District Hospital Basingstoke, Hants

Royal Berkshire Hospital, Reading, Berks

J M THOMAS

\section{Intravenous naftidrofuryl}

SIR,-In the report by Mr C R J Woodhouse and Mr D G A Eadie (21 May, p 1320) it was suggested that the intravenous infusion of $200 \mathrm{mg}(25 \mathrm{ml})$ of naftidrofuryl (Praxilene) was complicated by the development of "severe thrombophlebitis." The prospective study from which they drew this conclusion did not produce convincing results. Indeed, of the 13 infusion sites examined in their study, three had no evidence of thrombophlebitis at all and a further five developed varying degrees of thrombophlebitis only after multiple doses of naftidrofuryl. This rather negates their claim that "the thrombophlebitis began after only short periods of infusion and was particularly severe."

Intravenous naftidrofuryl has been used extensively in this unit and our findings are in agreement with those of $\mathrm{Mr} \mathrm{D}$ Charlesworth (11 June, p 1537). There is no evidence to suggest an increased amount of thrombophlebitis, even when the drug is given in smaller volumes of diluent. We usually dilute $200 \mathrm{mg}(25 \mathrm{ml})$ of naftidrofuryl solution in $250 \mathrm{ml}$ of low-molecular-weight dextran, without problems.

Donald G MacLellaN

Peripheral Vascular Unit,

Royal Infirmary,

Glasgow

\section{Diuretics and digoxin in myocardial infarction}

SIR,-The findings of $\mathrm{Dr} \mathrm{J} \mathrm{D}$ Hill and his colleagues (9 July, p 81) comparing mortality in the general ward and coronary care unit for patients with myocardial infarction is interesting, but of greater interest are the figures relating to the number of patients receiving digoxin or diuretics (table III).

Crepitations were recorded in $52.5 \%$ of all patients aged 65 or less (the distribution is not specified) and $47.9 \%$ were given diuretics. As no mention is made of other clinical or radiological parameters of cardiac failure the implication is that crepitations were considered a reasonable indication for the use of diuretics. That this is not so has been well documented. ${ }^{1}$
Diuretics may produce a significant fall in the optimal filling pressure of the infarcted left ventricle $^{2}$ and changes in potassium balance may aggravate the predisposition to arrhythmias. They should probably be reserved for patients with more definite evidence of cardiac failure (triple rhythm or $x$-ray changes) - certainly well fewer than half of patients with acute myocardial infarction.

The number of patients receiving digoxin is also surprisingly high $(33.7 \%$ overall). There is no good evidence that this drug is of value in acute myocardial infarction other than for the control of atrial fibrillation. Its positive inotropic effect may in theory lead to extension of infarct size $^{2}$ and the increased sensitivity of the ischaemic myocardium to its effects may exacerbate arrhythmias and make DC conversion of ventricular fibrillation difficult:

It would be of value to know what criteria were used for starting patients on diuretics or digoxin and to know what proportion of those patients in whom resuscitation was attempted, both successfully and unsuccessfully, was receiving these drugs.

The debate on home, general ward, or intensive coronary care will no doubt continue, but perhaps it is time we shifted our emphasis and looked critically at our prescribing habits for coronary patients.

RODNEY H FALK

Brook General Hospital,

London SE18

' Luepker, R V, et al, American fournal of Cardiology, Luepker, R V, et 1977, 39, 146.
Forrester, J S, et al, New England Fournal of Medicine,
1976, 295, 1404.

Resnekov, L, Medical Clinics of North America,
1976, 60, 325.

\section{Instant colour photography in} dermatology

SIR,-The advent of instant colour photography brings a clinically useful new means of accurately recording changes in acute dermatological cases. In this department we have been using an instant colour camera to record the evolution of rapidly changing skin lesion.

Having a very recent print available is of particular value in those few cases in which assessment of rate of change is used as a guide to management or effectiveness of therapy. Two recent cases illustrate this: (1) A 62-yearold woman with pemphigoid had recently been started on $120 \mathrm{mg}$ of prednisone per day. By knowing the exact extent of the lesions $12 \mathrm{~h}$ previously we were able to assess the need for change of steroid therapy. (2) The condition of a 48-year-old woman with an exacerbation of severe generalised pustular psoriasis was rapidly changing. With a series of instant photographs we were able to assess accurately the rate of improvement following change of therapy.

In most dermatological diseases the need for a photograph (transparency or otherwise) is not urgent and normal photography eventually produces a print of much higher quality than the instant result obtained here. However, it is regrettable that there are few available objective measurements of skin disorder which can be available for permanent inspection. The use of instant photography should therefore be seen as providing an added clinical photographic record in a few specific situations rather than in any way replacing present services. Negatives are not available and if it is thought that a slide might be needed a normal photograph also should be taken. The definition of the prints is reasonably good and the prints are relatively inexpensive.

A Y FINLAY

RONALD MARKS ERIC WADDINGTON

Department of Dermatology,

Cardiff

\section{Prevention and health}

SIR,-Professor I M Richardson rightly calls attention (9 July, $p$ 128) to the loss in the reorganised NHS of a local voice to draw public attention to matters of preventive medicine and promotion of health. Many community physicians share his concern. The old-style annual reports of the medical officer of health were time-consuming to produce and variable in quality, but the more imaginative and energetic medical officers could make their reports a valuable medium to convey health matters of local interest to their authorities and to the public in general.

Although individual responsibility for prevention may be less clearly defined in the new NHS I believe that community physicians must grasp the opportunities available to them locally to maintain and increase public awareness. The current vigorous public debate over prophylactic vaccines and the enthusiastic reception for the publication Prevention and Health: Everybody's Business ${ }^{1}$ indicate that the community is still receptive to information and ideas. There are fortunately still some means of communication open to us. For example, many community physicians are also medical officers for environmental health to local councils. A quarterly report on communicable disease or other environmental problems with local interest given to a committee can serve as an introduction to public advice on vaccination policy utilising the presence of the press.

Community health councils are interested in preventive matters and in my own region a successful seminar was held by them on the subject of "Prevention and health." Community physicians with management team responsibilities have, therefore, another useful means of making known through community health councils the health problems and policies in their districts.

Much needs to be done to produce goodquality data on which local preventive policies can be founded, and community physicians are often hampered in this task by lack of skilled support. Nevertheless, can we afford to neglect the few avenues of public information which the present organisation has allowed us to have?

York Health District Headquarters,
York

A Wilson McINTOSH

Department of Health and Social Security, Prevention and Health: Everybody's Business. London, HMSO, 1976.

SIR,-We should like to echo the regrets of Professor I M Richardson (9 July, p 128) that there is now no single spokesman responsible for the health of the local community.

In a recent case in which two healthy siblings of an intermittent excretor of Shigella sonnei have been kept off school for 12 weeks we have spoken to seven local community physicians, each of whom has claimed that 